\title{
Effects of trunk exercise with physioball to improve trunk balance among subjects with stroke: a systematic review and meta-analysis
}

\author{
Hariharasudhan Ravichandran ${ }^{1, *}$, Hidangmayum Richa Sharma², Tsiwaye Gebreyesus Haile' ${ }^{1}$, Asmare Yitayeh Gelaw³, \\ Berihu Fisseha Gebremeskel', Balamurugan Janakiraman ${ }^{3}$ \\ 'Department of Physiotherapy, School of Medicine, College of Health Sciences and Ayder Comprehensive Specialized Hospital, Mekelle University, Mekelle, Ethiopia \\ 2Department of Physiotherapy, Sakra Institute of Rehabilitation Sciences, Sakra World Hospital, Bengaluru, India \\ ${ }^{3}$ Department of Physiotherapy, School of Medicine, College of Medicine and Health Sciences, University of Gondar Comprehensive Specialized Hospital, University of \\ Gondar, Gondar, Ethiopia
}

Poststroke subjects present with difficulties of reduced functional mobility and balance. Trunk impairment is common among stroke subjects which hinder the performance of upper and lower limb. In poststroke rehabilitation limbs are provided much attention than the trunk. Trunk function has been identified as an important early predictor of functional outcome after stroke. Physioball is commonly used among healthy subjects in performing trunk exercises. This systematic review with meta-analysis is conducted to investigate the effect of trunk exercises performed using physioball in improving trunk performance after stroke. Six authors identified relevant articles from the following databases: PubMed, Google Scholar, CINAHL (Cumulative Index and Nursing and Allied Health Literature), PEDro (Physiotherapy Evidence Database). Articles evaluating the effect of physioball exercise for improving trunk stability among stroke subjects were included. Databases were screened from 2009 and up to 2019. Qualitative synthesis of evidence was prepared and meta-analysis was implemented to draw pooled effects of physioball exercise on improving trunk performance and balance among stroke subjects. Eight papers were included, totaling 273 participants. All the articles included in this review demonstrated moderate to good quality. Meta-analysis performed with seven papers demonstrated statistical significance of physioball in improving trunk performance during acute and subacute stages of stroke. Brunnel Balance Assessment outcomes demonstrated statistically significant improvement of balance among overall stroke survivors. Trunk exercise performed over a physioball is effective during the acute and subacute stage. This meta-analysis could not find its significant effect in improving trunk performance in the chronic stages.

Keywords: Stroke, Hemiplegia, Swiss ball, Physioball, Trunk impairment scale

\section{INTRODUCTION}

Stroke is a major global public health problem and it is the major cause of disability worldwide (Katan and Luft, 2018). Stroke is one of the main causes of mortality in adult populations of developed countries. In majority of the countries, stroke is the second or third cause of mortality (Ravichandran et al., 2019). Stroke survivors commonly have impaired motor control and balance that seriously affect their ability to lead an independent life and increasing burden to carers and society (Ravichandran and Janakiraman, 2016).

Basic trunk movement control is often impaired after stroke (Pappalardo et al., 2014). Malfunction of limb muscles in stroke is well documented, but little is known about the effect of stroke, in relation to trunk muscle activity. Unlike limb muscles, the innervation of trunk muscles is supplied from both cerebral hemispheres. The anterior corticospinal tract sends fibers mainly to the trunk or axial muscles. The control is both ipsilateral and contra-

\footnotetext{
${ }^{*}$ Corresponding author: Hariharasudhan Ravichandran (iD) https://orcid.org/0000-0002-0703-9675

Department of Physiotherapy, School of Medicine, College of Health Sciences and Ayder Comprehensive Specialized Hospital, Mekelle University, P.O. Box: 1871, Mekelle, Ethiopia

E-mail: hrkums63@gmail.com

Received: April 23, 2020 / Accepted: May 16, 2020
} 
lateral. Therefore, trunk muscles are bilaterally cortically innervated (Karatas et al., 2004). Due to this reason, unilateral stroke could potentially deteriorate the function of trunk muscles on both the contralateral and ipsilateral sides of the body (Dickstein et al., 2000). In general, the trunk muscles are activated before the movement of upper and lower limbs. The initiation of trunk muscles is delayed in stroke subjects because the muscles involved in reach arm are activated earlier than the trunk muscles. Moreover, a comparison test using isokinetic dynamometer for analyzing the strength of trunk flexors, extensors, and rotators showed that stroke patients had statistically significant weaker trunk muscles than healthy people (Bohannon, 1992). In a patient with stroke, the importance of trunk control is often neglected (Van Criekinge et al., 2018).

Trunk control needs to be preceded in order to control limb movements and is correlated with functional movements (Hsieh et al., 2002). Activities of daily living (ADL) require trunk stability and mobility. Howe et al. (2005) confirmed that the impairment of trunk muscle after stroke limits ADL. Trunk control is a crucial component to perform ADL. Thus, trunk muscle performance is an important factor in predicting the functional outcome among stroke subjects. It is therefore necessary to identify the effective strategy to enable improvement in trunk balance and mobility among subjects with stroke.

Studies evaluating therapy aimed at improving trunk function are limited. Studies (Howe et al., 2005; Saeys et al., 2012; Verheyden et al., 2007) showed that trunk control ability can be improved by performing specific exercise training. Verheyden et al. (2009) suggested that trunk exercises performed in all planes in the supine position, improved the ability to control the trunk in subacute stroke patients. Ryerson et al. (2008) stated that proprioceptive training is essential to improve trunk control and balance. Most of the conventional trunk rehabilitation among stroke subjects is performed in stable surface. Few studies (Jung et al., 2016; Van Criekinge et al., 2018; Yoo et al., 2014) and supported implementation of an unstable surface in trunk rehabilitation among stroke subjects. These authors reported on articles that included air cushion, balance board, physioball, balance pads, and so on to simulate unstable surface. Physioball is unstable device presently permeates the fitness and rehabilitation environment. Generally, physioball exercise for trunk increases the need for force output from trunk muscles to provide adequate stability and balance. Limited studies are available in the literature examining physioball as an intervention in trunk rehabilitation among stroke subjects. There is no systematic review available in the literature to critically appraise the research evidence on performing trunk exercise with physioball in improving trunk performance among stroke subjects. Due to its common application in rehabilitation, conducting a systematic review on physioball among stroke subjects would validate its effectiveness in improving trunk performance. The objective of this study is to analyze the effectiveness of trunk exercise performed with physioball measured through trunk impairment scale as outcome tool in trials among stroke subjects.

\section{MATERIALS AND METHODS}

\section{Eligibility criteria}

This systematic review protocol was registered in the international database of prospective register of systematic reviews (PROSPERO), CRD42020135810 and was performed collectively by six authors (Ravichandran H, Janakiraman B, Gelaw AY, Gebremeskel BF, Haile TG, and Sharma HR). The review was conducted according to the guidelines of Preferred Reporting Items for Systematic Reviews and Meta-Analyses (PRISMA) statement (Moher et al., 2015). Articles were selected according to the criteria mentioned below:

- Subjects with first onset, unilateral stroke.

- Minimum duration for onset of stroke is 10 days.

- Subjects aged 18-70 years.

- Both male and female genders.

- All randomized controlled trials, well-designed nonrandomized trials, and quasi-experimental designs intervening trunk exercise with physioball among stroke subjects.

- Articles using trunk impairment scale as outcome measure.

- Studies published in English and full-text availability.

- Studies were excluded if not having access to full test or articles published in languages other than English. Letters to the editor, comments, case reports, preclinical studies, and unpublished researches were also excluded.

\section{Search strategy}

Four authors (Ravichandran R, Janakiraman B, Gelaw AY, and Gebremeskel BF) conducted comprehensive search in January 2020, to identify articles published in databases such as PubMed, Cumulative Index and Nursing and Allied Health Literature (CINAHL), Physiotherapy Evidence Database (PEDro), and Google Scholar. The search was made using the following keywords or MeSH (medical subject heading) terms (if applicable); stroke or hemiplegia, and trunk stability or trunk balance, and physioball 
or Swiss ball or unstable surface, and trunk impairment or trunk impairment scale. Time restraints for the articles were set from 2009 and up to 2019. From 343 potentially appropriate articles, eight articles met the inclusion criteria of this review.

\section{Study selection}

Three authors (Janakiraman B, Haile TG, and Sharma HR) independently screened titles and abstracts to exclude articles out of scope. Eligible title and abstracts were retrieved for their full texts by two authors (Ravichandran $\mathrm{H}$ and Gelaw AY), to make selection decision according to the pre-established inclusion criteria. Any disagreements between the authors were resolved through consensus by discussing with author (Gebremeskel BF).

\section{Hierarchy of evidence}

Hierarchical system (Lloyd-Smith, 1997) was used to determine the level of evidence of included articles (Table 1). Two authors (Sharma HR and Gelaw AY) involved in this process and demonstrated that the articles included in this review had level of evidence ranged from $1 b$ to $2 b$ on hierarchy of evidence. In this study six randomized controlled trials, one nonrandomized controlled study and one quasi-experimental study design were included.

\section{Data extraction}

Three authors (Ravichandran H, Janakiraman B, and Gebremeskel $\mathrm{BF}$ ) extracted data independently using a structured data

Table 1. Lloyd-Smith Hierarchy of evidence

\begin{tabular}{|c|c|c|}
\hline $\begin{array}{l}\text { Level of } \\
\text { evidence }\end{array}$ & Study design & RCTs \\
\hline 1a & $\begin{array}{l}\text { Meta-analysis of randomized } \\
\text { controlled trials }\end{array}$ & \\
\hline $1 b$ & $\begin{array}{l}\text { Individual randomized controlled } \\
\text { study }\end{array}$ & $\begin{array}{l}\text { Bae et al. (2013) } \\
\text { Viswaja et al. (2015) } \\
\text { Cabanas- Valdés et al. (2016) } \\
\text { Ravichandran and Janakiraman } \\
\text { (2016) } \\
\text { Seo and Oh (2016) } \\
\text { Karthikbabu et al. (2011) }\end{array}$ \\
\hline $2 a$ & $\begin{array}{l}\text { Well-designed, nonrandomized } \\
\text { controlled study }\end{array}$ & Renald and Regan (2016) \\
\hline $2 b$ & $\begin{array}{l}\text { Well-designed } \\
\text { quasi-experimental study }\end{array}$ & Nayak et al. (2012) \\
\hline 3 & $\begin{array}{l}\text { Nonexperimental descriptive } \\
\text { studies-comparative/case studies }\end{array}$ & \\
\hline 4 & Respectable opinion & \\
\hline
\end{tabular}

RCT, randomized controlled trial. extraction form adapted from Cochrane Back Review Group (van Tulder et al., 2003). Key data that were extracted includes the following items; general study information (title of the article, year of publication, first author's last name, and geographical location of the study); design of the study and its characteristics (participant characteristics and outcome measures); outcome results with length of follow-up. Disagreements or conflicts during and after data extraction were resolved by a mutual agreement, and if needed, by requesting the opinion of the third reviewer (Haile TG).

\section{Quality appraisal}

All the authors independently evaluated the quality of included full-text articles, using quality assessment of controlled intervention studies tool developed by National Heart, Lung and Blood Institute (2014) of the National Institute of Health, United States. The quality of included articles was analyzed according to the 14 items listed in quality assessment of controlled intervention studies tool. One possible point was provided for each appraisal item if the included study fulfilled that item criteria. Based on the quality of included studies, the methodological quality assessed by this tool could range between 0 and 14 . The methodological quality for each article was determined based their scores. Scores of 0 to 4 were considered as low grade, 5 to 10 as moderate grade and 11 to 14 as high grade. All the authors were consistent in performing quality assessment of included studies. Discrepancies or consensus among the authors were resolved by discussion with an expert. In this study, three RCTs with scores between 11 and 14 were considered as high grade in quality and five articles with scores between 5 and 10 were considered as moderate in quality. None of the included articles were low in quality (Table 2).

\section{Risk of bias}

Three authors (Ravichandran H, Gebremeskel BF, and Sharma HR) independently scrutinized the articles for potential risk of bias using the Cochrane Collaboration tool for risk of bias (Sterne et al., 2019). The domains formally assessed were sequence generation, allocation concealment, blinding of participants and personnel, blinding of outcome assessment, incomplete outcome data, selective reporting, and other bias (Table 3).

\section{Statistical analysis}

Meta-analysis was performed using Cochrane's Review Manager (RevMan) software (The Cochrane Collaboration, 2014). The effect sizes for continuous outcomes were expressed by mean difference in all trials. Mean difference with $95 \%$ confidence interval 
Table 2. Quality assessment of controlled intervention studies

\begin{tabular}{|c|c|c|c|c|c|c|c|c|}
\hline Criteria & $\begin{array}{c}\text { Bae et al. } \\
\text { (2013) }\end{array}$ & $\begin{array}{l}\text { Cabanas- } \\
\text { Valdés et al. } \\
\text { (2016) }\end{array}$ & $\begin{array}{l}\text { Karthikbabu } \\
\text { et al. } \\
\text { (2011) }\end{array}$ & $\begin{array}{l}\text { Nayak et al. } \\
\text { (2012) }\end{array}$ & $\begin{array}{l}\text { Ravichandran and } \\
\text { Janakiraman } \\
\text { (2016) }\end{array}$ & $\begin{array}{l}\text { Renald and } \\
\text { Regan } \\
(2016)\end{array}$ & $\begin{array}{l}\text { Seo and Oh } \\
(2016)\end{array}$ & $\begin{array}{c}\text { Viswaja et al. } \\
\text { (2015) }\end{array}$ \\
\hline $\begin{array}{l}\text { 1. Was the study described as randomized, a } \\
\text { randomized trial, a randomized clinical trial, } \\
\text { or an RCT? }\end{array}$ & Yes & Yes & Yes & No & Yes & No & No & Yes \\
\hline $\begin{array}{l}\text { 2. Was the method of randomization adequate } \\
\text { (i.e., use of randomly generated assignment)? }\end{array}$ & Yes & Yes & Yes & No & Yes & Yes & No & Yes \\
\hline $\begin{array}{l}\text { 3. Was the treatment allocation concealed } \\
\text { (so that assignments could not be predicted)? }\end{array}$ & Yes & Yes & Yes & No & Yes & Not reported & Not reported & Yes \\
\hline $\begin{array}{l}\text { 4. Were study participants and providers } \\
\text { blinded to treatment group assignment? }\end{array}$ & Not reported & Yes & No & $\begin{array}{l}\text { No (single- } \\
\text { blinded) }\end{array}$ & Yes & Not reported & No & Not reported \\
\hline $\begin{array}{l}\text { 5. Were the people assessing the outcomes } \\
\text { blinded to the participants' group assignments? }\end{array}$ & Not reported & Yes & Yes & Yes & Yes & Yes & No & Not reported \\
\hline $\begin{array}{l}\text { 6. Were the groups similar at baseline on } \\
\text { important characteristics that could affect } \\
\text { outcomes (e.g., demographics, risk factors, } \\
\text { comorbid conditions)? }\end{array}$ & Yes & Yes & Yes & Yes & Yes & Not reported & Yes & Yes \\
\hline $\begin{array}{l}\text { 7. Was the overall drop-out rate from the study } \\
\text { at endpoint } 20 \% \text { or lower of the number } \\
\text { allocated to treatment? }\end{array}$ & Yes & Yes & Yes & Yes & Yes & Yes & Yes & Yes \\
\hline $\begin{array}{l}\text { 8. Was the differential drop-out rate (between } \\
\text { treatment groups) at endpoint 15\% points or } \\
\text { lower? }\end{array}$ & Yes & Yes & Yes & Yes & Yes & Yes & Yes & Yes \\
\hline $\begin{array}{l}\text { 9. Was there high adherence to the intervention } \\
\text { protocols for each treatment group? }\end{array}$ & Yes & Yes & Yes & Yes & Yes & Yes & Yes & Yes \\
\hline $\begin{array}{l}\text { 10. Were other interventions avoided or similar in } \\
\text { the groups (e.g., similar background } \\
\text { treatments)? }\end{array}$ & Yes & Yes & Yes & Yes & Yes & Yes & Yes & Yes \\
\hline $\begin{array}{l}\text { 11. Were outcomes assessed using valid and } \\
\text { reliable measures, implemented consistently } \\
\text { across all study participants? }\end{array}$ & Yes & Yes & Yes & Yes & Yes & Yes & Yes & Yes \\
\hline $\begin{array}{l}\text { 12. Did the authors report that the sample size } \\
\text { was sufficiently large to be able to detect a } \\
\text { difference in the main outcome between } \\
\text { groups with at least } 80 \% \text { power? }\end{array}$ & No & Yes & No & Yes & No & No & No & Not reported \\
\hline $\begin{array}{l}\text { 13. Were outcomes reported or subgroups } \\
\text { analyzed prespecified (i.e., identified before } \\
\text { analyses were conducted)? }\end{array}$ & No & No & No & No & No & No & No & No \\
\hline $\begin{array}{l}\text { 14. Were all randomized participants analyzed in } \\
\text { the group to which they were originally } \\
\text { assigned, i.e., did they use an } \\
\text { intention-to-treat analysis? }\end{array}$ & Yes & Yes & Yes & Yes & Yes & Yes & Yes & Yes \\
\hline Scores & $10 / 14$ & $13 / 14$ & $11 / 14$ & $9 / 14$ & $12 / 14$ & $8 / 14$ & $7 / 14$ & $10 / 14$ \\
\hline
\end{tabular}

RCT, randomized controlled trial.

(CI) was used to determine changes in outcomes between physioball group and control group. This review considered a $P$-value of $<0.05$ to be statistically significant. The study by Nayak et al. (2012) was a single group quasi-experimental design and hence it was excluded from meta-analysis. Four separate meta-analysis were performed, using Trunk Impairment Scale and Brunnel Balance Assessment as the outcome measure: (a) effect size of phys- ioball intervention in improving trunk performance during acute stage of stroke; (b) effect size of physioball intervention in improving trunk performance during subacute stage of stroke; (c) effect size of physioball intervention in improving trunk performance during chronic stage of stroke; (d) effect size of physioball intervention in improving balance among stroke survivors. 
Table 3. Risk of bias analysis

\begin{tabular}{lcccccccc}
\hline Bias & $\begin{array}{c}\text { Bae et al. } \\
\text { (2013) }\end{array}$ & $\begin{array}{c}\text { Cabanas-Valdés } \\
\text { et al. (2016) }\end{array}$ & $\begin{array}{c}\text { Karthikbabu } \\
\text { et al. (2011) }\end{array}$ & $\begin{array}{c}\text { Nayak et al. } \\
(2012)\end{array}$ & $\begin{array}{c}\text { Ravichandran and } \\
\text { Janakiraman (2016) }\end{array}$ & $\begin{array}{c}\text { Renald and } \\
\text { Regan (2016) }\end{array}$ & $\begin{array}{c}\text { Seo and Oh } \\
(2016)\end{array}$ & $\begin{array}{c}\text { Viswaja et al. } \\
(2015)\end{array}$ \\
\hline Selection of participants & Low risk & Low risk & Low risk & High risk & Low risk & Low risk & Unclear & Low risk \\
Allocation concealment & Unclear & Low risk & Low risk & High risk & Low risk & Unclear & $\begin{array}{c}\text { Unclear } \\
\text { Unclear }\end{array}$ \\
Blinding of participants & Unclear & High risk & High risk & High risk & Low risk & High risk & High risk & High risk \\
Assessor blinding & Unclear & Low risk & Low risk & Low risk & Low risk & Low risk & High risk & High risk \\
Incomplete data & Low risk & Low risk & Low risk & Low risk & Low risk & Low risk & Low risk & Low risk \\
Selective reporting & Low risk & Low risk & Low risk & Low risk & Low risk & Low risk & Low risk & Low risk \\
Other bias & Low risk & Low risk & Low risk & Low risk & Low risk & Low risk & Low risk & Low risk \\
\hline
\end{tabular}

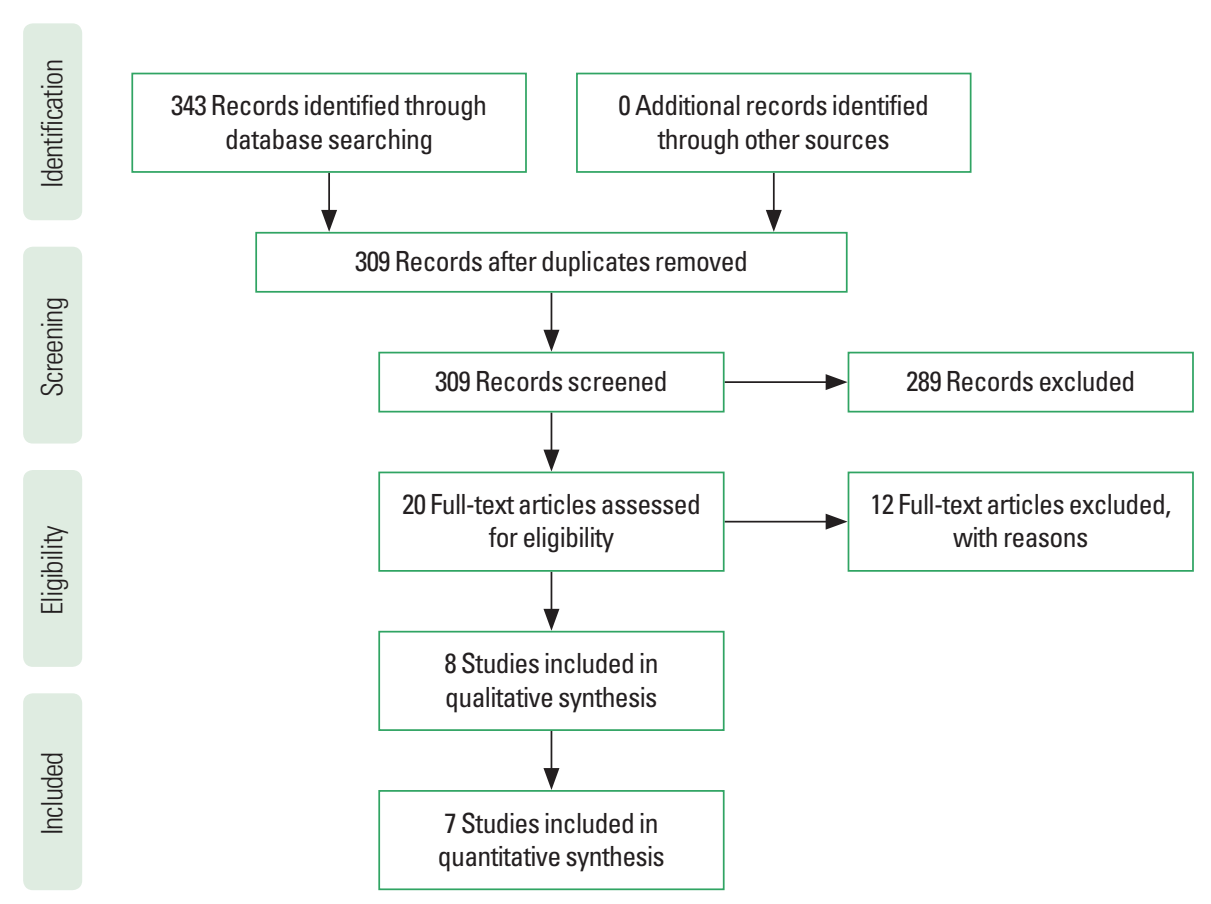

Fig. 1. Prisma flow diagram illustrating the study selection process.

\section{RESULTS}

\section{Study selection}

A total of 343 articles were identified in the initial search strategy. After the titles were screened, 34 articles were excluded as duplicates and 289 articles excluded because they did not meet the eligibility criteria. Of the 20 selected articles, 12 were excluded as they did not contemplate the objective of this review. Finally, eight articles were included in this review, out of which seven articles were included in the meta-analysis. The PRISMA flow diagram in Fig. 1 illustrates the study selection process.

\section{Participants}

Eight articles included a total of 273 participants, with 143 pa- tients allocated to physioball intervention group and 130 participated in the comparative group. All studies included in this meta-analysis are from Asia and Europe. Mean age (standard deviation) of the participants included in the articles ranged between 49.2 (4.3) to 75.68 (9.4). The majority of participants were women. Ischaemic stroke was more prevalent among the participants and participants commonly affected on their right side of the body. Two articles have not reported the mean age, gender, causes of stroke, and side of body affected. Among the eight articles, 3 articles intervened among acute stroke subjects, 3 articles on subacute stroke subjects, and 2 articles performed with chronic stroke subjects. All the interventions were performed in hospital settings under the supervision of a therapist. The length of follow-up varied from 2 weeks to 12 weeks (Table 4). The mean 


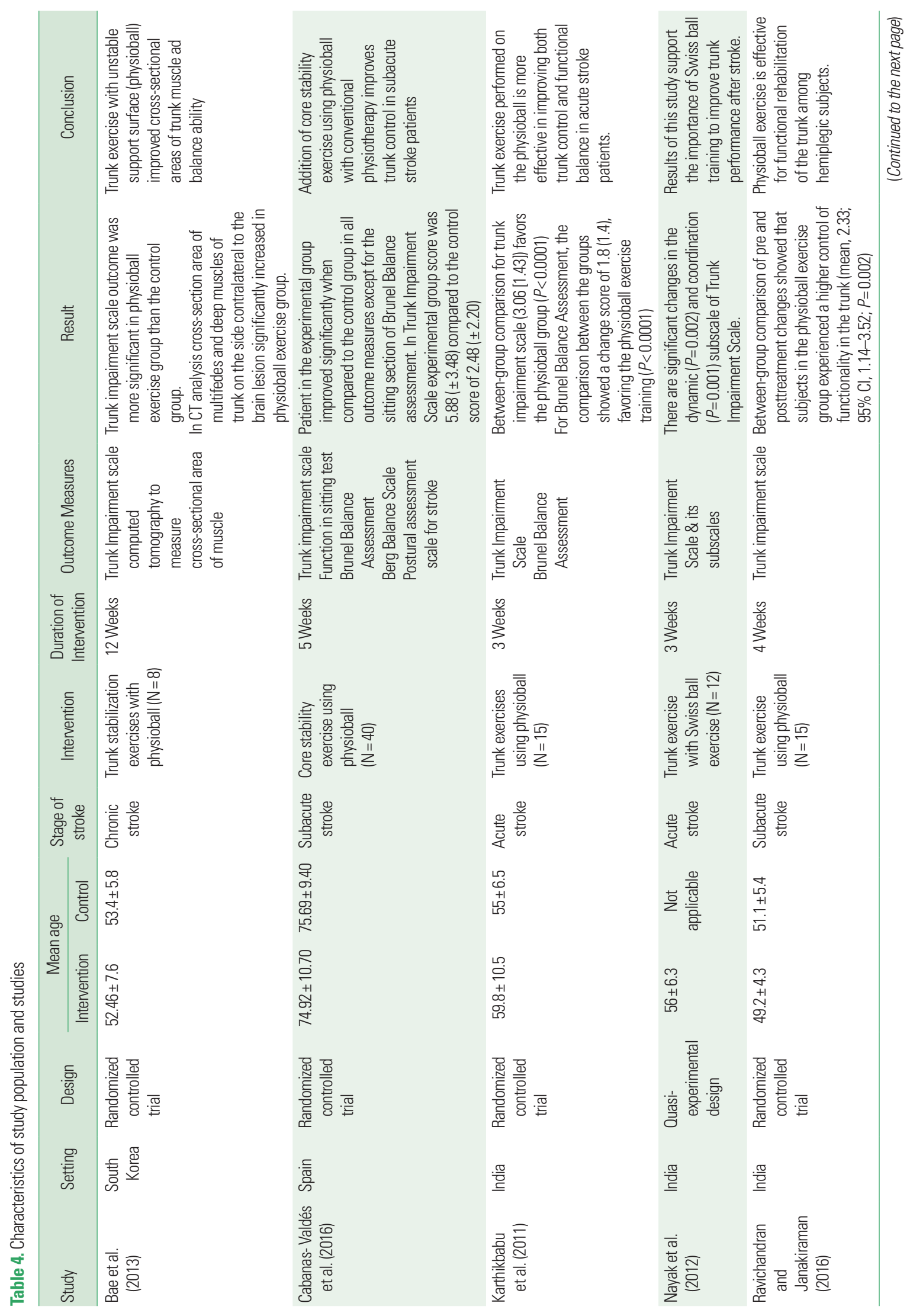




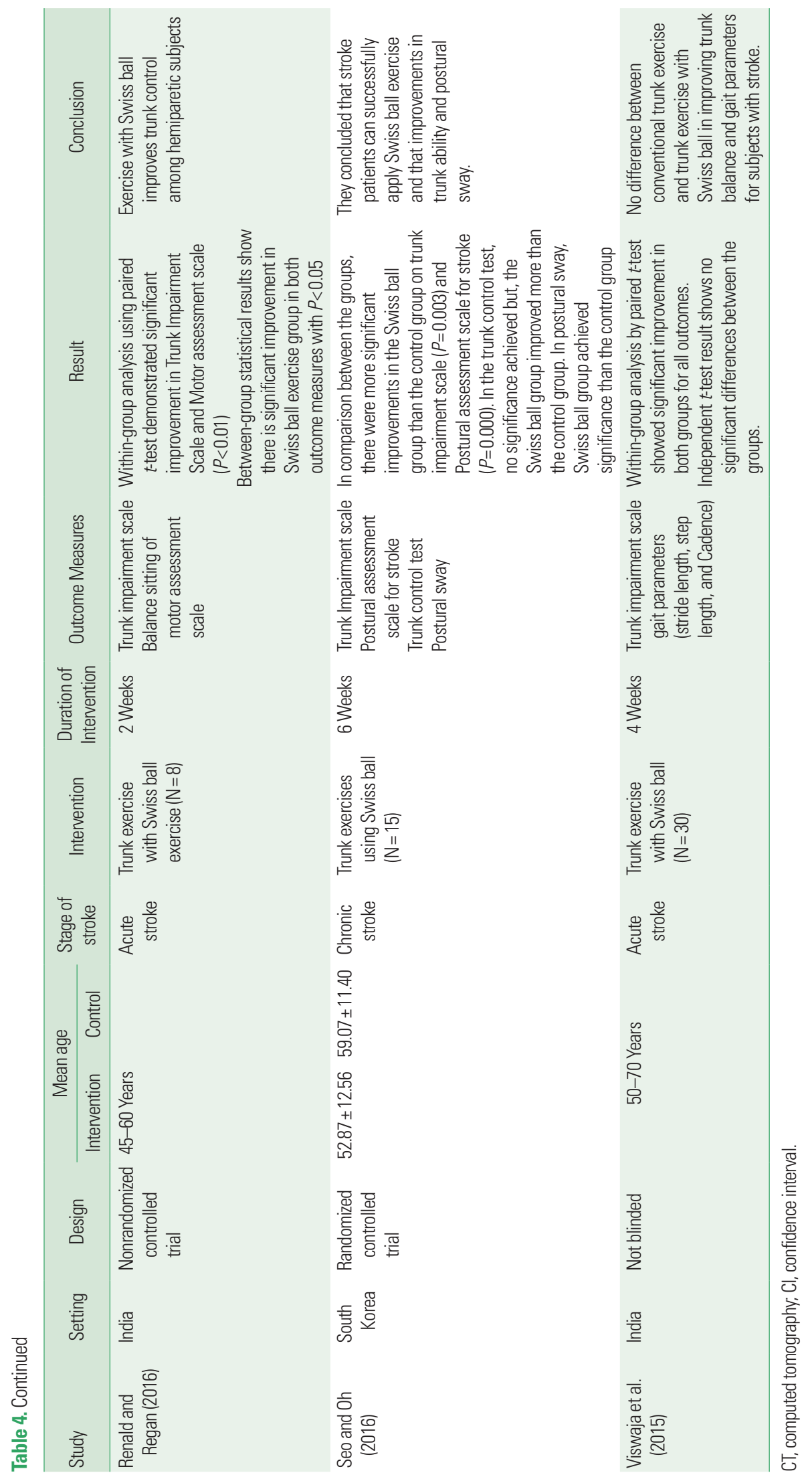




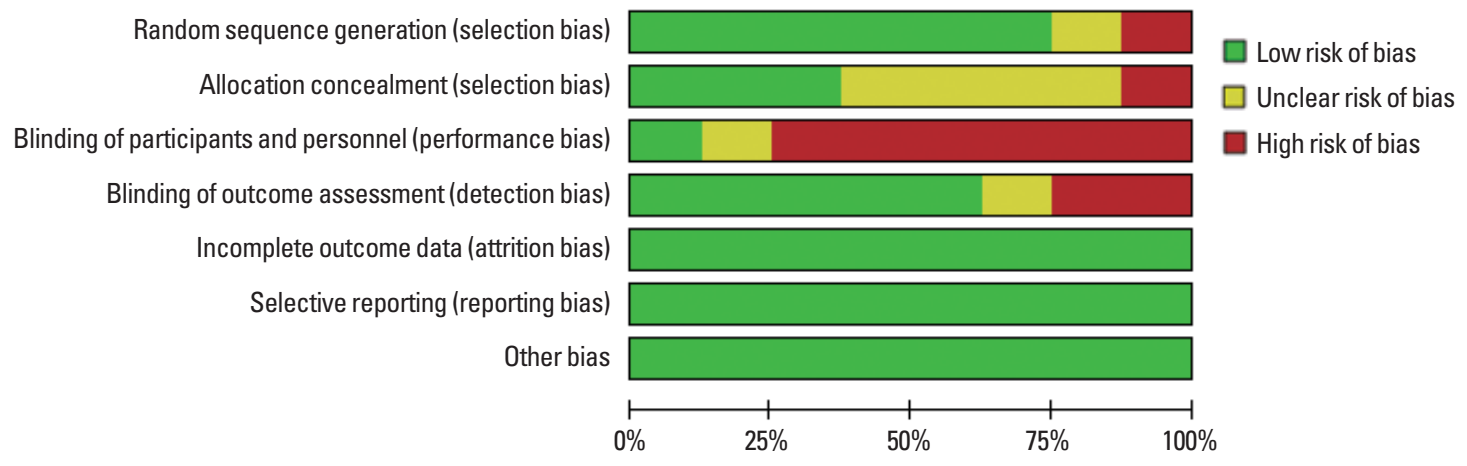

Fig. 2. Risk of bias percentage graph.

quality of the included articles was 10 out of a total of 14 possible points. To determine the interrater reliability of authors Cohen Kappa was calculated (Kappa $=0.83$ ) and found to be almost perfect agreement.

\section{Risk of bias within studies}

Randomization and allocation concealment demonstrated high risk in the quasi-experimental study performed by Nayak et al. (2012). Random sequence generation was reported in six articles and it was unclear in Seo and Oh (2016). Allocation concealment had low risk in three articles and was unclear in four articles (Bae et al., 2013; Renald and Regan, 2016; Seo and Oh, 2016; Viswaja et al., 2015). Blinding of participants was not performed in six studies and unclearly reported in one study. Outcome assessor was not blinded in two studies and unclear information was reported in one study. There was no incomplete data and selective reporting in the articles included and hence they had low risk. Ravichandran and Janakiraman (2016) had low risk in all the domains. The results of risk of bias were demonstrated in Figs. 2 and 3. The interrater Cohens Kappa statistics was 0.891.

\section{Effect size of physioball intervention in improving trunk performance during acute stage of stroke}

Three articles with 106 participants examined the trunk impairment scale outcome using physioball intervention during the acute stage (Fig. 4). The overall effect size (standardized mean difference) of 1.52 (95\% CI, 0.88-2.16) suggests a large effect with high percentage of heterogeneity (88\%). The study by Viswaja et al. (2015) with the largest treatment effect (2.86), reported a raw between-group effect size of 19.2. The other two studies, that favoring physioball intervention had large treatment effects of 0.00 and 1.75 , respectively. Pooled estimation showed that physioball exercise is effective in improving trunk performance during the

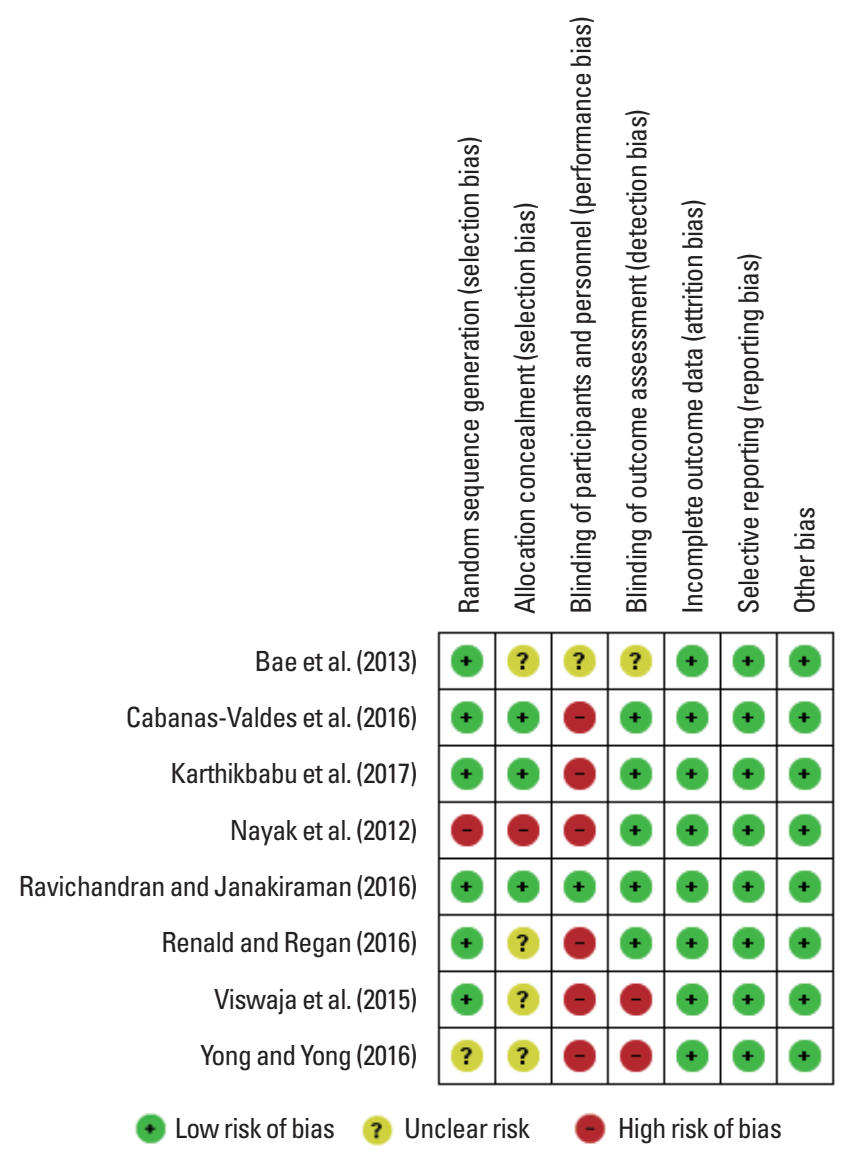

Fig. 3. Risk of bias assessment of included studies.

acute stage of stroke with $P<0.00001$.

\section{Effect size of physioball intervention in improving trunk performance during subacute stage of stroke}

Two studies investigated trunk impairment scale outcome using physioball intervention during the subacute stage among 109 participants. The pooled estimation resulted in a significant effect size 


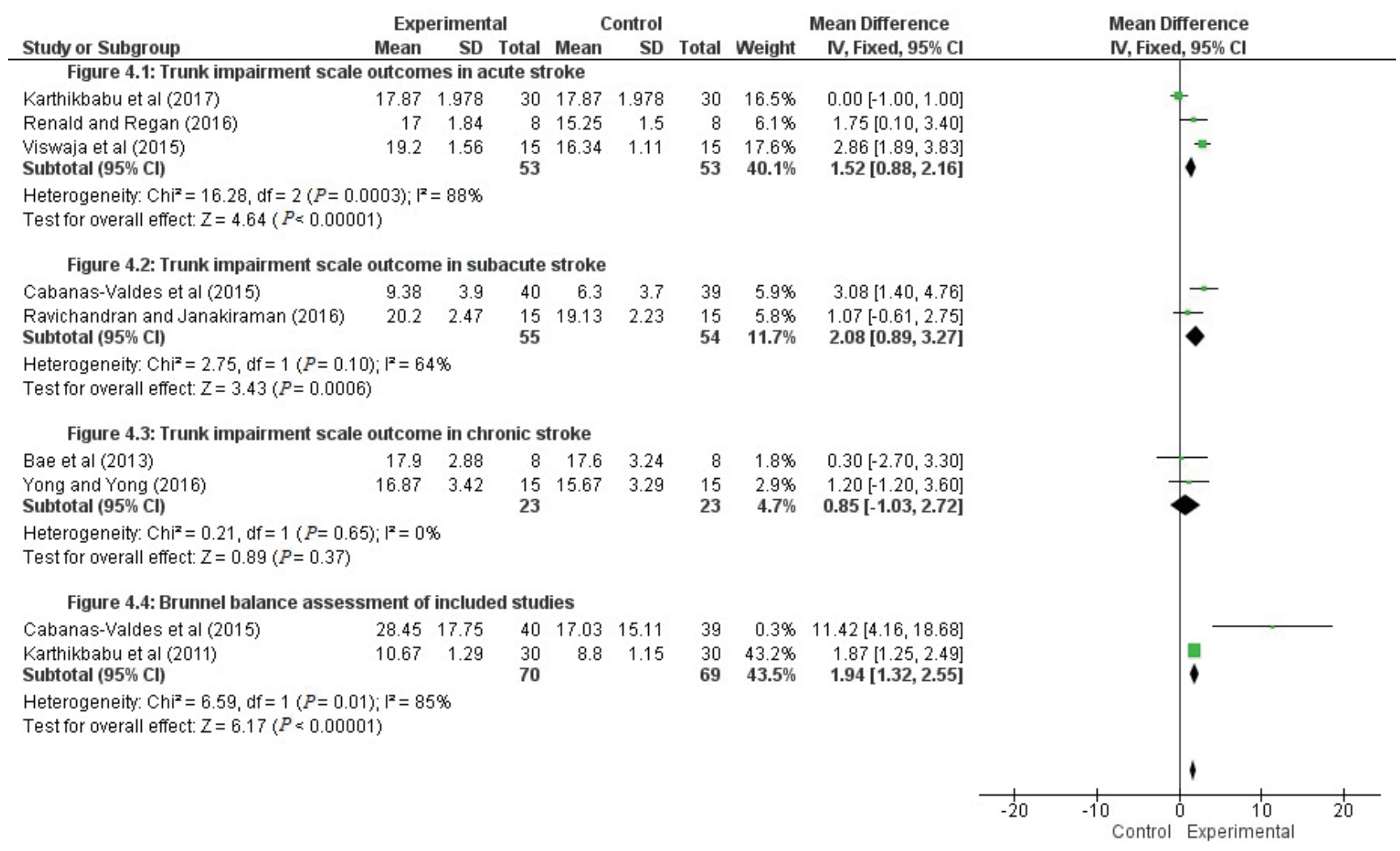

Fig. 4. Meta-analysis of outcomes. SD, standard deviation; Cl, confidence interval; IV, weighted mean difference.

of 2.08 (95\% CI, 0.89-3.27) with moderate heterogeneity of $\mathrm{I}^{2}=$ $64 \%$ (Fig. 4). Treatment effect was large (3.08) in the study by Cabanas-Valdés et al. (2016). Statistically significant $P=0.0006$ value favors that physioball exercise is effective in improving trunk impairment scale among subacute stroke patients.

\section{Effect size of physioball intervention in improving trunk performance during chronic stage of stroke}

Two studies investigating significance of physioball exercise in improving trunk impairment scale among 46 chronic stroke subjects were illustrated in Fig. 4. The overall effect size (standardized mean difference) of 0.85 ( $95 \% \mathrm{CI},-1.03$ to 2.72 ) with low heterogeneity of $0 \%$. Statistical result $(P=0.37)$ of these two articles does not favor physioball exercise among chronic stroke subjects in improving trunk impairment scale outcomes.

\section{Effect size of physioball intervention in improving balance among stroke survivors}

The effect of physioball exercise in improving trunk balance was examined by pooling of data from Brunnel Balance Assessment from two studies involving 139 subjects. The overall effect size was 1.94 (95\% CI, 1.32-2.55) with higher heterogeneity of $85 \%$ (Fig. 4). Statistically significant $P$-value of 0.00001 indicates that physioball exercise has a significant effect in improving balance of stoke subjects measured by Brunnel Balance Assessment.

\section{Adverse effects}

None of the eight articles included in this review have reported on adverse effects during or after the intervention. Cabanas-Valdés et al. (2016) reported death as a reason for excluding a control group participant in their randomized controlled trial.

\section{Publication bias}

Funnel plots were used to illustrate the risk of publication bias. The funnel plots for physioball exercise in improving trunk performance and balance among stroke survivors, resembles symmetrical, demonstrating a lower likelihood for publication bias. However, the results of funnel plots of this meta-analysis could be influenced by lower number of articles included in the literature. The authors suggest that this meta-analysis demonstrates a lower to moderate chances for publication bias. 


\section{DISCUSSION}

This meta-analysis was performed to demonstrate the effects of physioball exercise in improving trunk performance among stroke subjects. There were no meta-analysis or systematic review performed in the past to evaluate the effectiveness of physioball in improving trunk performance among stroke subjects. To the best of our knowledge, this is the first meta-analysis to focus on the evidence concerning the effects of physioball exercise among stroke subjects.

Trunk impairment scale measuring the outcome of physioball exercise among stroke populations was set as an eligibility criterion to include article in this meta-analysis. Trunk impairment scale has been considered as a prediction instrument in the rehabilitation setting when considering the prognosis of stroke patients (Verheyden et al., 2007). There is variation in the type, intensity, and duration of physioball intervention implemented in the articles included for this review. The overall effect is good as demonstrated in the dynamic and coordination subscales of trunk impairment scale.

Articles included in this systematic review and meta-analysis demonstrated variance in comparison groups, intervention protocol, intervention duration, outcome measures, and quality of study. Heterogeneity rate was high in this meta-analysis due to small number of articles included and variance across the studies. The probable mechanism by which physioball could have worked is by facilitating the trunk control. Trunk exercise on the physioball poses a biomechanical demand on the trunk muscles. Postural perturbation experienced while exercising the trunk on the physioball is also another factor to facilitate trunk activity. Trunk exercise with physioball promotes anticipatory activation by maintaining the synergy between groups of muscles (Lehman et al., 2005). Exercising in a physioball facilitates postural control, trunk control, sitting, and dynamic balance control by maintaining interaction between nervous system, musculoskeletal system and contextual effects. These effects could not be achieved easily while exercising on the stable surface. The study results of Nagle (2011) also advocates on the positive effect of physioball exercises on the strength of abdominal and back muscles and balance to improve the performance for combat sports.

The result of this systematic review is similar to the previous review conducted by Behm et al. (2015). In that systematic review, 22 RCTs implementing unstable surfaces (Swiss ball, air cushion, balance board, and so on) for trunk training were included and their result concluded that unstable surface is effective in improving muscle strength, power and balance when compared to the controls. Recently another study, investigated the effect of trunk rehabilitation using unstable surfaces, on static and dynamic balance after stroke and with the evidence of seven RCTs, it concluded that trunk training on unstable support surface seemed to be superior to stable support surfaces in improving static and dynamic balance (Van Criekinge et al., 2018). These studies support the fact that unstable surface has beneficial effect in improving trunk performance.

Performing trunk exercise on a physioball is an area of concern needed in the literature. Trunk exercises performed with physioball is effective in improving trunk performance among hemiplegic subjects. More than improving trunk performance, physioball has the potential to facilitate upper limb and lower limb muscle cocontractions, which in turn improves the functional recovery following stroke. The results of this meta-analysis suggest that trunk exercise performed on the physioball has the potential to improve trunk performance for stroke survivors.

This meta-analysis provides insight into physioball exercises in improving trunk balance and stability for stroke subjects. The results of this meta-analysis emphasize the importance of focusing on stroke rehabilitation with unstable surfaces. First limitation of this study is there is limited availability of studies in the literature. Secondly, there exists a variance in diversity of stroke, side of stroke, and causes of stroke among the articles included in this meta-analysis. Thirdly, there exist differences in post interventional follow-up and lack of retention effect follow-up among the articles included in this review. Additionally, the authors could not able to trace the unpublished data or articles published in other language version to analyze the effect of publication bias.

\section{CONCLUSIONS}

The results of this study conclude that physioball exercise improves trunk performance and balance among subjects with stroke. Meta-analysis of included articles reveals that trunk improvement was significant during the acute and subacute stages of stroke. However, high percentage of heterogeneity suggests that more high quality randomized controlled trials with larger sample size in the future are required to justify this conclusion.

\section{CONFLICT OF INTEREST}

No potential conflict of interest relevant to this article was reported. 


\section{ACKNOWLEDGMENTS}

We sincerely thank the College of Medicine and Health Sciences, of the Mekelle University and University of Gondar for helping us with the internet service, online library access, and library services during the review process.

\section{REFERENCES}

Bae SH, Lee HG, Kim YE, Kim GY, Jung HW, Kim KY. Effects of trunk stabilization exercises on different support surfaces on the cross-sectional area of the trunk muscles and balance ability. J Phys Ther Sci 2013;25:741-745.

Behm DG, Muehlbauer T, Kibele A, Granacher U. Effects of strength training using unstable surfaces on strength, power and balance performance across the lifespan: a systematic review and meta-analysis. Sports Med 2015;45:1645-1669.

Bohannon RW. Lateral trunk flexion strength: impairment, measurement reliability and implications following unilateral brain lesion. Int J Rehabil Res 1992;15:249-251.

Cabanas-Valdés R, Bagur-Calafat C, Girabent-Farrés M, Caballero-Gómez FM, Hernández-Valiño M, Urrútia Cuchí G. The effect of additional core stability exercises on improving dynamic sitting balance and trunk control for subacute stroke patients: a randomized controlled trial. Clin Rehabil 2016;30:1024-1033.

Dickstein R, Sheffi S, Ben Haim Z, Shabtai E, Markovici E. Activation of flexor and extensor trunk muscles in hemiparesis. Am J Phys Med Rehabil 2000;79:228-234.

Howe TE, Taylor I, Finn P, Jones H. Lateral weight transference exercises following acute stroke: a preliminary study of clinical effectiveness. Clin Rehabil 2005;19:45-53.

Hsieh CL, Sheu CF, Hsueh IP, Wang CH. Trunk control as an early predictor of comprehensive activities of daily living function in stroke patients. Stroke 2002;33:2626-2630.

Karatas M, Cetin N, Bayramoglu M, Dilek A. Trunk muscle strength in relation to balance and functional disability in unihemispheric stroke patients. Am J Phys Med Rehabil 2004;83:81-87.

Karthikbabu S, Nayak A, Vijayakumar K, Misri Z, Suresh B, Ganesan S, Joshua AM. Comparison of physio ball and plinth trunk exercises regimens on trunk control and functional balance in patients with acute stroke: a pilot randomized controlled trial. Clin Rehabil 2011;25:709719.

Katan M, Luft A. Global Burden of Stroke. Semin Neurol 2018;38:208-211. Jung KS, Cho HY, In TS. Trunk exercises performed on an unstable surface improve trunk muscle activation, postural control, and gait speed in patients with stroke. J Phys Ther Sci 2016;28:940-944.

Lehman GJ, Gordon T, Langley J, Pemrose P, Tregaskis S. Replacing a Swiss ball for an exercise bench causes variable changes in trunk muscle activity during upper limb strength exercises. Dyn Med 2005;4:6.

Lloyd-Smith W. Evidence-based practice and occupational therapy. Br J Occup Ther 1997;60:474-478.

Moher D, Shamseer L, Clarke M, Ghersi D, Liberati A, Petticrew M, Shekelle P, Stewart LA; PRISMA-P Group. Preferred reporting items for systematic review and meta-analysis protocols (PRISMA-P) 2015 statement. Syst Rev 2015;4:1.

Nagle E. Effect of swiss ball exercises on some physical and physiological variables and their relationship with kata performance level. J Phys Edu Sport 2011;11:56-64.

National Heart, Lung and Blood Institute (NHLBI). Study quality assessment tools. Bethesda (MD): NHLBI; 2014

Nayak A, Kumar V, Babu K. Does training on swiss ball improve trunk performance after stroke? - A single blinded, quasi experimental study design. Indian J Physiother Occup Ther 2012;6:172-175.

Pappalardo A, Ciancio MR, Patti F. Is the basic trunk control recovery different between stroke patients with right and left hemiparesis? NeuroRehabilitation 2014;35:215-220.

Ravichandran $\mathrm{H}$, Janakiraman B. Enhancing trunk stability in acute poststroke subjects using physioball exercise and proprioceptive neuromuscular facilitation technique: a pilot randomized controlled trial. Int J Adv Med Health Res 2016;3:5-10.

Ravichandran H, Janakiraman B, Sundaram S, Fisseha B, Gebreyesus T, Yitayeh Gelaw A. Systematic review on effectiveness of shoulder taping in hemiplegia. J Stroke Cerebrovasc Dis 2019;28:1463-1473.

Renald SF, Regan JR. Efficacy of trunk exercises on swiss ball versus bed in improving trunk control in hemiparetic patients. Int J Physiother Res 2016;4:1444-1450.

Ryerson S, Byl NN, Brown DA, Wong RA, Hidler JM. Altered trunk position sense and its relation to balance functions in people post-stroke. J Neurol Phys Ther 2008;32:14-20.

Saeys W, Vereeck L, Truijen S, Lafosse C, Wuyts FP, Heyning PV. Randomized controlled trial of truncal exercises early after stroke to improve balance and mobility. Neurorehabil Neural Repair 2012;26:231238.

Seo YJ, Oh YS. Effect of swiss ball exercise on trunk ability and postural sway in stroke patients. Asian J Kinesiol 2016;18:71-80

Sterne JAC, Savović J, Page MJ, Elbers RG, Blencowe NS, Boutron I, Cates CJ, Cheng HY, Corbett MS, Eldridge SM, Emberson JR, Hernán MA, Hopewell S, Hróbjartsson A, Junqueira DR, Jüni P, Kirkham JJ, Lasserson T, Li T, McAleenan A, Reeves BC, Shepperd S, Shrier I, Stewart LA, Tilling K, White IR, Whiting PF, Higgins JPT. RoB 2: a revised tool 
for assessing risk of bias in randomised trials. BMJ 2019;366:14898.

The Cochrane Collaboration. Review Manager (RevMan) [computer program]. Version 5.3. Copenhagen (Denmark): The Cochrane Collaboration; 2014.

Van Criekinge T, Saeys W, Vereeck L, De Hertogh W, Truijen S. Are unstable support surfaces superior to stable support surfaces during trunk rehabilitation after stroke? A systematic review. Disabil Rehabil 2018;40:1981-1988.

van Tulder M, Furlan A, Bombardier C, Bouter L; Editorial Board of the Cochrane Collaboration Back Review Group. Updated method guidelines for systematic reviews in the cochrane collaboration back review group. Spine (Phila Pa 1976) 2003;28:1290-1299.

Verheyden G, Nieuwboer A, De Wit L, Feys H, Schuback B, Baert I, Jenni
W, Schupp W, Thijs V, De Weerdt W. Trunk performance after stroke: an eye catching predictor of functional outcome. J Neurol Neurosurg Psychiatry 2007;78:694-698.

Verheyden G, Vereeck L, Truijen S, Troch M, Lafosse C, Saeys W, Leenaerts E, Palinckx A, De Weerdt W. Additional exercises improve trunk performance after stroke: a pilot randomized controlled trial. Neurorehabil Neural Repair 2009;23:281-286.

Viswaja K, Pappala KP, Tulasi PS, Apparao P. Effectiveness of trunk training versus swiss ball exercises for improving sitting balance and gait parameters in acute stroke subjects. Int J Physiother 2015;2:925-932.

Yoo J, Jeong J, Lee W. The effect of trunk stabilization exercise using an unstable surface on the abdominal muscle structure and balance of stroke patients. J Phys Ther Sci 2014;26:857-859. 